University of Nebraska - Lincoln

DigitalCommons@University of Nebraska - Lincoln

2012

Integration Technologies for Silicon Carbide-Based Ceramics for

Micro-Electro-Mechanical Systems-Lean Direct Injector Fuel Injector Applications

\author{
Michael C. Halbig \\ NASA Glenn Research Center, michael.c.halbig@nasa.gov \\ Mrityunjay Singh \\ NASA Glenn Research Center, mrityunjay.singh-1@nasa.gov \\ Hiroshi Tsuda \\ Osaka Prefecture University, tsuda@mtr.osakafu-u.ac.jp
}

Follow this and additional works at: https://digitalcommons.unl.edu/nasapub

Halbig, Michael C.; Singh, Mrityunjay; and Tsuda, Hiroshi, "Integration Technologies for Silicon CarbideBased Ceramics for Micro-Electro-Mechanical Systems-Lean Direct Injector Fuel Injector Applications" (2012). NASA Publications. 114.

https://digitalcommons.unl.edu/nasapub/114

This Article is brought to you for free and open access by the National Aeronautics and Space Administration at DigitalCommons@University of Nebraska - Lincoln. It has been accepted for inclusion in NASA Publications by an authorized administrator of DigitalCommons@University of Nebraska - Lincoln. 


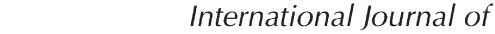 \\ Applied
Ceramic \\ TECHNOLOGY
}

Ceramic Product Development and Commercialization

\section{Integration Technologies for Silicon Carbide-Based Ceramics for Micro-Electro-Mechanical Systems-Lean Direct Injector Fuel Injector Applications}

\author{
Michael C. Halbig* \\ NASA Glenn Research Center, Cleveland, Ohio, 44135 \\ Mrityunjay Singh \\ NASA Glenn Research Center, Ohio Aerospace Institute, Cleveland, Ohio, 44135
}

Hiroshi Tsuda

Graduate School of Engineering, Osaka Prefecture University, Sakai, Osaka, 599-8531, Japan

Advanced joining approaches are critically needed for the fabrication and integration of silicon carbide-based micro-electromechanical systems lean direct fuel injectors for jet engines. Diffusion bonding of silicon carbide with titanium interlayers offers advantages such as uniform application/surface coverage and no flow of the interlayer or the reaction formed phases during joint processing. The resulting joints were uniform, stable, leak free, and had high strength. Titanium interlayers with 10 and $20 \mu \mathrm{m}$ thicknesses were obtained from physical vapor deposition (PVD) and pure metallic foils. The effects of the interlayer type and thickness and processing time on the resultant microstructures were investigated. The joints and their reaction-formed phases were analyzed with electron microprobe analysis and scanning electron microscopy coupled with energy-dispersive spectroscopy, ultrasonic immersion nondestructive evaluation method, and transmission electron microscopy. For the physical vapor deposition $\mathrm{Ti}_{\mathrm{i}}$ interlayers, the $10 \mu \mathrm{m}$ coating gave the best results yielding a joint that did not have intermediate phases or microcracking. For the Ti foil interlayers, the joint processed with a 4 h-hold time had more stable phases and less microcracking than those with 1 and $2 \mathrm{~h}$-hold times. The average tensile strength of the diffusion bonds was 14.2 MPa which was 2-3 times higher than the application requirements. The diffusion bonding approach was shown to meet the requirements for SiC-based fuel injector fabrication. 


\section{Introduction}

Silicon carbide (SiC)-based ceramics are being developed or are already being used in a wide variety of high temperature and structural applications including armor, ${ }^{1}$ actuators and sensors, ${ }^{2,3}$ micro-electro-mechanical systems (MEMS), ${ }^{4-6}$ nuclear components, ${ }^{7}$ optical mirrors, ${ }^{8,9}$ and in ceramic matrix composites (CMCs) for nuclear applications ${ }^{10-12}$ and gas turbine engines. ${ }^{12-15}$ Favorable properties of $\mathrm{SiC}$ include high melting temperature, high strength, low coefficient of thermal expansion, creep resistance, high thermal conductivity, corrosion resistance, and thermal shock resistance.

The specific application which is the focus of this article is a silicon carbide-based MEMS lean direct fuel injector $^{16}$ to be used in jet engines. There are two potential injector approaches, (i) a lean premixed preevaporated (LPP) injector; and (ii) a lean direct injector (LDI). The LPP approach has an advantage in that it produces the most uniform temperature distribution and lowest possible NOx emissions. However, a disadvantage is that it cannot be used in high pressure ratio aircraft engines due to auto-ignition and flashback. The LDI design was selected due its advantages in that it does not have the problems of a LPP injector (autoignition and flashback) and it provides extremely rapid mixing of the fuel and air before combustion occurs. ${ }^{17}$ An illustration of the LDI injector is shown in Fig. 1. It is made up of several laminates each of which has its own surface profile and hole pattern which form such features as the fuel holes, air swirlers, fuel cavities, and through holes for the combustion air. To build up the component, the silicon carbide laminates are stacked in sequence and joined to form internal flow circuits for the fuel and the by-pass air which is efficiently mixed at the exit side of the injector. Although the injector's application temperature will be well below the temperature capabilities of silicon carbide, there are several benefits to its utilization in this application. Silicon carbide could potentially allow for the laminate sections to be mass produced using batch etching processes rather than shaped by complex machining. In addition, the silicon carbide is a favorable material due to its thermal and chemical compatibility with sensor and actuator components that will be integrated into the injector. Integrated sensors and actuators will allow for improved flow monitoring, active combustion control, lean burning, and correction of combustion instabilities. At the exiting surface, the fuel and combustion air mix to pro-

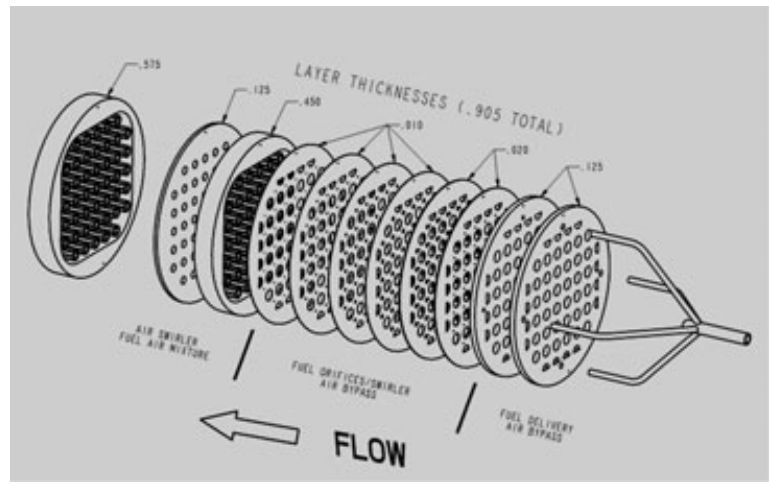

Fig. 1. Illustration of the lean direct injector design.

vide efficient combustion with low emissions and low NOx. Joining approaches will be demonstrated in a simplified version of the injector which has only three laminate sections. The actual parts for the injector are shown in Fig. 2.

A variety of joining methods are being developed for building up complex-shaped $\mathrm{SiC}$ components from simpler shapes fabricated by such methods as hot pressing, sintering, reaction bonding, and chemical vapor deposition (CVD). Joining can offer lower costs for fabricating components compared to the expense of processing thick, 3-D parts that may require advanced processing methods and extensive machining. The joining methods being developed include reaction bonding, glass bonding, brazing, and diffusion bonding. In reaction bonding carbonaceous mixtures are reacted with silicon carbide ${ }^{9,18}$ or silicon ${ }^{19,20}$ to form silicon carbide. Different types of polymers ${ }^{21,22}$ have also been used for $\mathrm{SiC}$ bonding with limited success. Active brazing with the $\mathrm{Ag}-\mathrm{Cu}-\mathrm{Ti}$ alloy had been used to join $\mathrm{SiC}^{23}$ and had shown good success. Transient liquid phase (TLP) bonding has also been developed in which multiple interlayers are used to form joints through the formation of a thin transient liquid phase layer at temperatures that are typically several hundred degrees lower than those required for more traditional joining methods. ${ }^{24,25}$ Hille et $\mathrm{al}^{7}$ used brazing fillers of $\mathrm{Y}_{2} \mathrm{O}_{3}-\mathrm{Al}_{2} \mathrm{O}_{3}$ $-\mathrm{SiO}_{2}$ to join $\mathrm{SiC}$ using a laser beam. Diffusion bonding of silicon carbide has also been performed with the use of interlayers of Inconel $600,{ }^{26}$ nickel, ${ }^{27}$ and titanium. ${ }^{28,29}$

Requirements for the SiC bonding technology for the current application include the ability to join relatively large, flat geometries (i.e., $10.16 \mathrm{~cm}$ diameter 


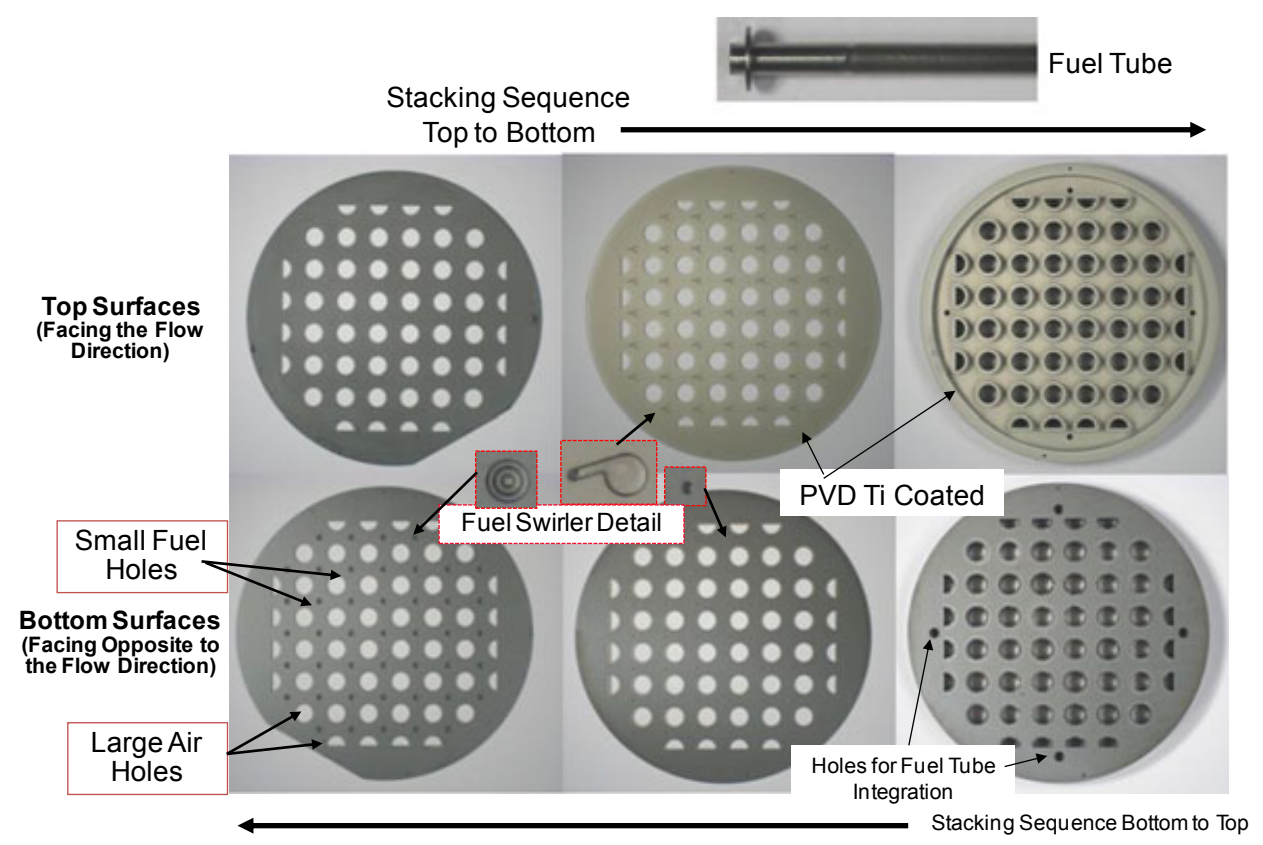

Fig. 2. The three laminate injector parts for demonstration of component fabrication. The fuel tube is shown at the top with a higher magnification for illustration. Each laminate is $10.16 \mathrm{~cm}$ in diameter.

disks), leak-free operation, and chemical and mechanical stability for long durations (i.e., thousands of hours) at operation conditions. The $\mathrm{SiC}$ injector will be exposed to internal pressures of $1.38 \mathrm{MPa}$ and a temperature of $450^{\circ} \mathrm{C}$. Technical challenges which must be overcome to develop robust joining approaches include the formation of nonuniform bonds and open voids across the substrates, the formation of residual stresses during the cool-down stage after processing, and chemical incompatibility between the substrates, the starting bond material and the subsequent reaction formed phases. The stresses form due to thermal expansion mismatches between the two joined materials and the interlayers and can lead to microcracking. These technical challenges can be alleviated with the proper selection of joining interlayers and processing conditions.

In the present work, the diffusion bonding approach was selected to join $\mathrm{SiC}$ ceramic subelements. This approach allows for a uniform interlayer that can be applied as a coating or inserted as a foil with a cut out pattern to match the surface that is to be bonded. The diffusion bonding method is not expected to have any complications due to flow of the interlayer material or its reaction formed phases. A previous approach using silicate glass had complications due to glass flow that resulted in nonuniform bonds, leaks between laminates, and plugs in the small fuel holes at the exiting surface of the injector. The diffusion bonding approach, which requires the use of a hot press, is well suited to the design of the injector with its flat 2-D laminates. The work reported in this article has focused on optimization and characterization of the bonding technology to ensure that it meets the requirements for the injector fabrication and utilization.

\section{Experimental Procedure}

Joints of $\mathrm{SiC}-\mathrm{SiC}$ were processed using a diffusion bonding approach which was conducted at elevated temperatures in a vacuum environment with the aid of a hot press and joining interlayers. The commercially available CVD $\beta-S i C$ materials were obtained from Rohm \& Hass (Woburn, MA). Two different interlayers were used for joining. The first was titanium metallic foil from Goodfellow (Glen Burnie, MD) with a purity level of $99.6 \%$ and thicknesses of 10 and $20 \mu \mathrm{m}$. The second interlayer was titanium coating with a thickness of $10 \mu \mathrm{m}$ which was applied in-house onto $\mathrm{SiC}$ substrate surfaces using physical vapor deposition 
(PVD). For joining with the PVD Ti coating interlayer, surfaces with one coated and one uncoated substrate and with two coated substrates were matched to obtain 10 and $20 \mu \mathrm{m}$ thick interlayers, respectively. Prior to joining, the materials (uncoated $\mathrm{SiC}$ substrates, coated $\mathrm{SiC}$ substrates, and cut metallic foils) were ultrasonically cleaned in acetone for $10 \mathrm{~min}$. Joints using the PVD $\mathrm{Ti}$ coated $\mathrm{SiC}$ were processed at a temperature of $1250^{\circ} \mathrm{C}$, clamping pressure of $24 \mathrm{MPa}, 2$ h-hold in a vacuum environment, and cooling rate of $5^{\circ} \mathrm{C} / \mathrm{min}$. Joints with the Ti foil as the interlayer were processed at a temperature of $1200^{\circ} \mathrm{C}$, clamping pressure of $30 \mathrm{MPa}$, and cooling rate of $5^{\circ} \mathrm{C} / \mathrm{min}$. The joint formed with the $10 \mu \mathrm{m}$ foil had a $2 \mathrm{~h}$-hold. The three joints formed with the $20 \mu \mathrm{m}$ foil had hold times of 1,2 , and $4 \mathrm{~h}$. For joining conducted with the PVD Ti coatings, the $\mathrm{SiC}$ substrates had machined dimensions of $50.8 \mathrm{~mm} \times$ $25.4 \mathrm{~mm} \times 1.5 \mathrm{~mm}$. The resulting jointed samples were cut in half and one of the halves was used for microscopy. For joining with the Ti foils, smaller SiC substrates were used so that the machining step after joining could be avoided and dimensions were $25.4 \mathrm{~mm} \times 12.7 \mathrm{~mm} \times 1.5 \mathrm{~mm}$. All diffusion bonded samples were mounted in epoxy and polished in preparation for microstructural analysis of the cross sections. Once mounted in epoxy, the surfaces were rough ground down to a depth of about $3 \mathrm{~mm}$ and then polished to a smooth surface. Elemental analysis and phase identification was conducted on carbon-coated samples using electron microprobe analysis (EMPA) for the bonds formed with PVD $\mathrm{Ti}$ and using scanning electron microscopy (SEM) for bonds formed with the Ti foil. Both were coupled with energy dispersive spectroscopy (EDS).

Transmission electron microscopy (TEM) was conducted on selected joined samples. TEM samples were prepared by using a focused ion beam (FIB) with gallium $(\mathrm{Ga})$ as the ion source for micro machining a thin slice of constant thickness from a precise location on the sample. TEM sample preparation by FIB followed the procedure summarized below and described in detail in the literature. ${ }^{30}$ Prior to cutting out the thin slice, the sample surface was coated with a carbon layer to protect the material from the ion beam. The ion beam was used to machine two parallel trenches on both sides of the sample area to be observed. The resulting wall constituted the parallel-sided thin slice. The FIB was equipped with an internal micromanipulator for extracting the slice. Through TEM specimen preparation by FIB, a clean, less damaged, and precisely selected thin specimen was successfully obtained compared to other methods such as ion milling.

Additional joints were fabricated to advance the joining technology toward application in the $\mathrm{SiC}$ injector component. To evaluate NDE methods and the joint quality, diffusion bonds were processed on two sets of PVD $\mathrm{SiC}$ disks that were $2.54 \mathrm{~cm}$ diameter. One pair of SiC substrates had a polished surface so that they had a black mirror-like finish and the other set was unaltered so that it had a nonreflective gray finish. For each of the two joining pairs, the surface of one of the substrates had a $10 \mu \mathrm{m}$ thick PVD Ti coating applied to the $1.66 \mathrm{~cm}$ inner diameter of the substrate. After bonding, these two sets of joined disks were nondestructively evaluated (NDE) using ultrasonic immersion. Following NDE analysis, the disks were fracture tested to determine the strength of the bonds. In preparation for strength testing, the top and bottom surfaces of the joined samples were adhered to test fixtures and then the tensile pull tests were conducted. The fracture surfaces were analyzed under an optical microscope. Diffusion bonding was also used to join a pair of $10.16 \mathrm{~cm}$ diameter $\mathrm{SiC}$ disks in which one of the substrates had a $10 \mu \mathrm{m}$ PVD Ti coating on one surface. The other substrate has a hole array through its thickness to simulate the holes to which metallic fuels tubes would be integrated. The diffusion bond was processed at a temperature of $1200^{\circ} \mathrm{C}$, clamping pressure of $30 \mathrm{MPa}, 4 \mathrm{~h}$-hold, and cooling rate of $5^{\circ} \mathrm{C} /$ min. Joining of the $10.16 \mathrm{~cm}$ disks was conducted to demonstrate and characterize joining on larger parts that are the same size as the injector parts. A section was cut from the joined disk and mounted in epoxy and polished in preparation for microscopy using SEM.

\section{Results and Discussion}

\section{Joint Microstructure}

The resulting diffusion bonds from using the PVD $\mathrm{Ti}$ coatings as the joining interlayer are shown in the microprobe images in Figs. 3 and 4 for the 20 and $10 \mu \mathrm{m}$ thick layers, respectively. The compositions as determined by EDS analysis are shown in Table I for all the phases identified in the diffusion bonds. Phase identifications in the joint are based upon the average of 3-5 analyses of different locations across the sample for regions of similar appearance and composition. The 
(a)

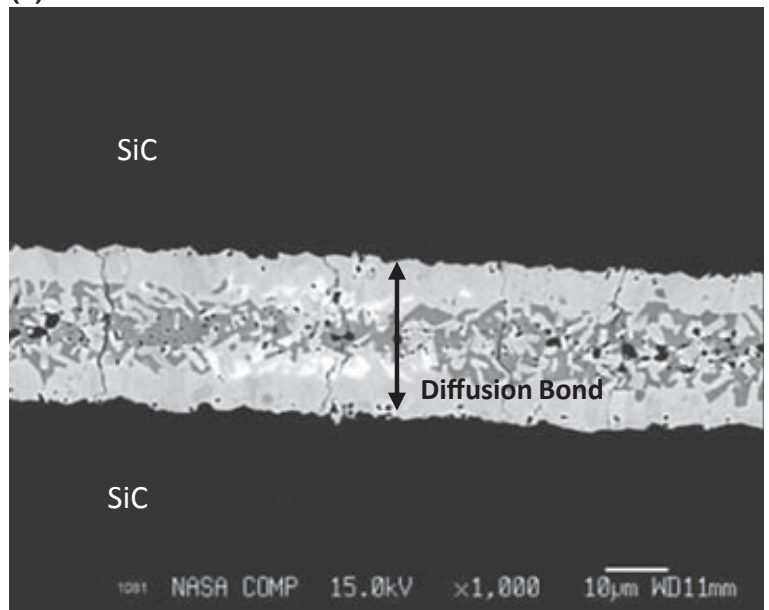

(b)

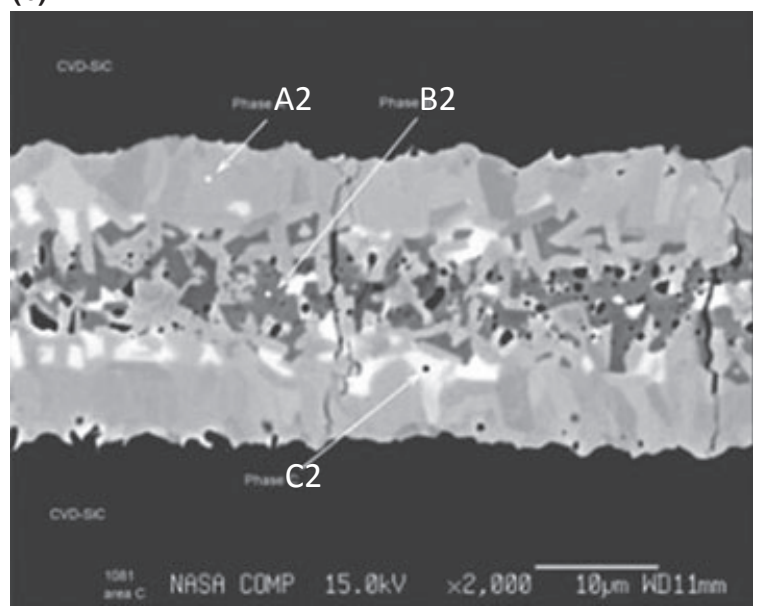

Fig. 3. (a) and (b) EMPA micrograph of the diffusion bond from $20 \mu \mathrm{m} P V D$ Ti at $1250^{\circ} \mathrm{C}$ with 2 h-hold.

bond from the thicker $20 \mu \mathrm{m}$ layer was observed to have microcracks and the presence of three phases. The phases labeled as A2, B2, and C2 in Fig. 3 were identified as $\mathrm{Ti}_{3} \mathrm{SiC}_{2}, \mathrm{TiSi}_{2}$, and $\mathrm{Ti}_{5} \mathrm{Si}_{3}\left(\mathrm{C}_{\mathrm{x}}\right)$, respectively. The microcracks may be due to a single factor or a combination of factors. One likely factor is due to the presence of the reaction formed phase of $\mathrm{Ti}_{5} \mathrm{Si}_{3} \mathrm{C}_{\mathrm{x}}$ (C2 in Fig. 3) which occurred in regions between the core of the diffusion bond and the edge of the $\mathrm{SiC}$ substrates. The $\mathrm{Ti}_{5} \mathrm{Si}_{3} \mathrm{C}_{\mathrm{x}}$ phase with its low at. $\%$ of carbon is also noted in literature as $\mathrm{Ti}_{5} \mathrm{Si}_{3}$. The titanium silicide phase $\left(\mathrm{Ti}_{5} \mathrm{Si}_{3}\right)$ has anisotropic thermal expansion. ${ }^{31,32}$ The coefficient of thermal expansion (CTE) is $6.11 \mathrm{ppm} / \mathrm{K}$ in the a-direction and $16.62 \mathrm{ppm} / \mathrm{K}$ in (a)

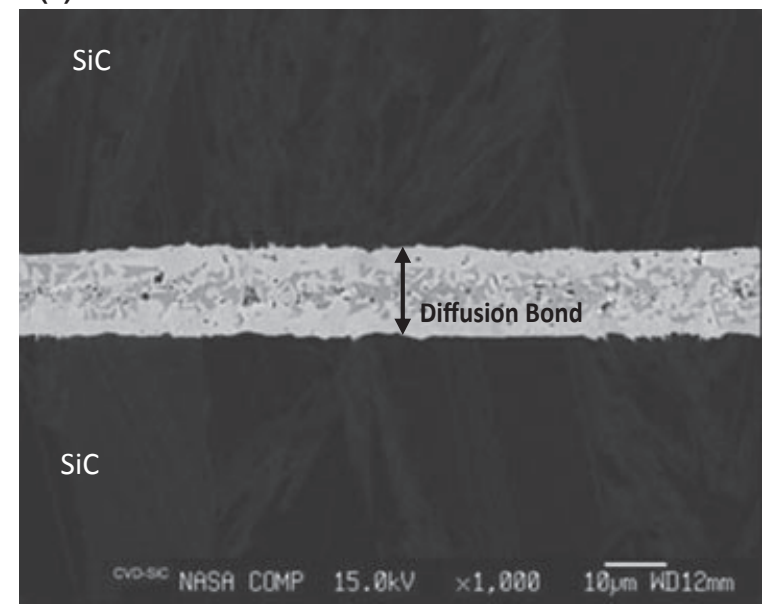

(b)

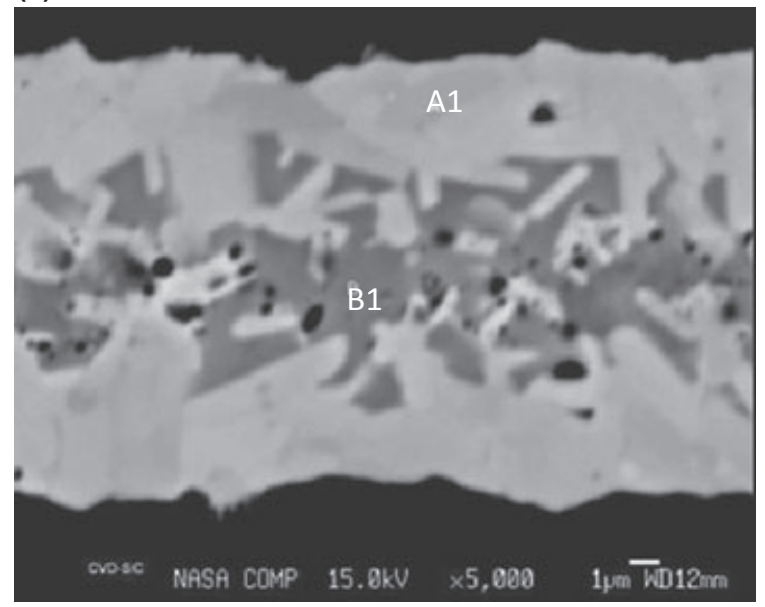

Fig. 4. (a) and (b) EMPA micrograph of the diffusion bond from $10 \mu \mathrm{m}$ PVD Ti at $1250^{\circ} \mathrm{C}$ with 2 h-hold.

the c-direction, with a ratio of CTE(c)/CTE(a) equal to 2.72. Other researchers have reported a higher anisotropy ratio of $4.39 .^{33}$ As the joint is cooled after processing, the CTE mismatches may cause thermal stresses which contribute to microcracking. The bond formed with the thinner $10 \mu \mathrm{m}$ layer, as seen in Fig. 4, did not have microcracking. The two phases of $\mathrm{Ti}_{3} \mathrm{SiC}_{2}$ (Phase A1) and $\mathrm{TiSi}_{2}$ (Phase B1) were again identified which is consistent with the results by Gottselig et al. ${ }^{29}$ for the temperature range of $1000-1250^{\circ} \mathrm{C}$. The phase of $\mathrm{Ti}_{5} \mathrm{Si}_{3} \mathrm{C}_{\mathrm{x}}$ was not observed in this thinner bond. Naka et al. ${ }^{34}$ also suggested that $\mathrm{Ti}_{5} \mathrm{Si}_{3} \mathrm{C}_{\mathrm{x}}$ is an intermediate phase that will not be present when phase reactions have gone to completion. This seems to be 
Table I. Compositions of the Resulting Diffusion Bonds

\begin{tabular}{|c|c|c|c|c|c|c|}
\hline \multirow{2}{*}{$\begin{array}{l}\text { Joining interlayer/hold time/ } \\
\text { temperature }\end{array}$} & \multirow{2}{*}{$\begin{array}{l}\text { Phase } \\
\text { label }\end{array}$} & & \multicolumn{3}{|c|}{ Composition in at. $\%$} & \multirow{2}{*}{$\begin{array}{c}\text { Probable } \\
\text { phase }\end{array}$} \\
\hline & & & C & Si & Ti & \\
\hline \multirow[t]{2}{*}{$10 \mu \mathrm{m} \mathrm{PVD} \mathrm{Ti} / 2 \mathrm{~h} / 1250^{\circ} \mathrm{C}$} & \multirow{2}{*}{$\begin{array}{l}\mathrm{A} 1 \\
\mathrm{~B} 1\end{array}$} & \multicolumn{2}{|r|}{25} & 19 & 56 & $\mathrm{Ti}_{3} \mathrm{SiC}_{2}$ \\
\hline & & \multicolumn{2}{|r|}{3} & 61 & 36 & $\mathrm{TiSi}_{2}$ \\
\hline \multirow[t]{3}{*}{$20 \mu \mathrm{m}$ PVD Ti $/ 2 \mathrm{~h} / 1250^{\circ} \mathrm{C}$} & \multirow{2}{*}{$\mathrm{A} 2$} & \multicolumn{2}{|r|}{26} & 18 & 56 & $\mathrm{Ti}_{3} \mathrm{SiC}_{2}$ \\
\hline & & \multicolumn{2}{|r|}{2} & 62 & 36 & $\mathrm{TiSi}_{2}$ \\
\hline & $\begin{array}{l}\mathrm{B} 2 \\
\mathrm{C} 2\end{array}$ & \multicolumn{2}{|r|}{7} & 34 & 59 & $\mathrm{Ti}_{5} \mathrm{Si}_{3}\left(\mathrm{C}_{\mathrm{x}}\right)$ \\
\hline \multirow[b]{2}{*}{$\begin{array}{l}\text { Joining interlayer/hold time/ } \\
\text { temperature }\end{array}$} & \multirow[b]{2}{*}{$\begin{array}{l}\text { Phase } \\
\text { label }\end{array}$} & \multicolumn{3}{|c|}{ Composition in at. $\%$} & \multirow{2}{*}{\multicolumn{2}{|c|}{$\begin{array}{l}\text { Common and unique phases } \\
\text { among the four joints }\end{array}$}} \\
\hline & & C & Si & $\mathbf{T i}$ & & \\
\hline \multirow[t]{3}{*}{$10 \mu \mathrm{m}$ Ti Foil $/ 2 \mathrm{~h} / 1200^{\circ} \mathrm{C}$} & A & 51 & 14 & 35 & \multicolumn{2}{|c|}{ Common A } \\
\hline & $\mathrm{B}$ & 38 & 27 & 35 & \multicolumn{2}{|c|}{ Common B } \\
\hline & $\mathrm{C}$ & 37 & 43 & 20 & \multicolumn{2}{|c|}{ Unique to this condition } \\
\hline \multirow[t]{3}{*}{$20 \mu \mathrm{m}$ Ti Foil $/ 1 \mathrm{~h} / 1200^{\circ} \mathrm{C}$} & A & 54 & 13 & 33 & \multicolumn{2}{|c|}{ Common A } \\
\hline & B & 44 & 23 & 33 & \multicolumn{2}{|c|}{ Common B } \\
\hline & $\mathrm{C}$ & 57 & 1 & 42 & \multicolumn{2}{|c|}{$\begin{array}{l}\text { Common A with lower } \\
\text { Si content }\end{array}$} \\
\hline \multirow[t]{3}{*}{$20 \mu \mathrm{m}$ Ti Foil $/ 2 \mathrm{~h} / 1200^{\circ} \mathrm{C}$} & A & 55 & 13 & 32 & Comms & \\
\hline & $\mathrm{B}$ & 47 & 22 & 31 & Commo & \\
\hline & $\mathrm{C}$ & 58 & 7 & 35 & $\begin{array}{l}\text { Commo } \\
\text { Si con }\end{array}$ & ower \\
\hline $20 \mu \mathrm{m}$ Ti Foil $/ 4 \mathrm{~h} / 1200^{\circ} \mathrm{C}$ & A & 53 & 14 & 33 & Comms & \\
\hline & $\mathrm{B}$ & 42 & 25 & 33 & Comme & \\
\hline $10 \mu \mathrm{m} \mathrm{PVD} \mathrm{Ti} / 4 \mathrm{~h} / 1200^{\circ} \mathrm{C}$ & A & 50 & 14 & 36 & Commo & \\
\hline from large joined disks & $\mathrm{B}$ & 34 & 28 & 38 & Commo & \\
\hline & $\mathrm{C}$ & 57 & 9 & 34 & $\begin{array}{r}\text { Commo } \\
\text { Si con }\end{array}$ & ower \\
\hline
\end{tabular}

Note: Phase labels correlate with the corresponding micrograph.

supported by the results presented herein. Both of the joints with the 10 and $20 \mu \mathrm{m}$ interlayers were processed during a 2 h-hold. The joint for the thicker layer had the detrimental intermediate anisotropic phase while in the thinner joint the phase was absent and more stable phases are assumed to have formed. Better bond quality and a lower density of defects in thinner $\mathrm{Ti}$ interlayers were also noted by Cockeram ${ }^{28}$ in which bonding with 5.1 and $25 \mu \mathrm{m}$ Ti foils was investigated. The dark pores which appear in the bonds may be due to the formation of more dense phases during the diffusion bonding process. The pores which are very small and isolated are not expected not have a significant effect on the mechanical and leakage properties of the bond.
The diffusion bonds formed with the 10 and $20 \mu \mathrm{m}$ thick Ti foils are shown in Figs. 5-8 and the compositions of the phases identified in each joint are provided in Table I. Each of the four joints had two of the same phases that are labeled as phase A and phase $\mathrm{B}$ in Table I and in the corresponding micrographs. The composition for phase A was in the range of 51$55 \mathrm{C} / 13-14 \mathrm{Si} / 32-35 \mathrm{Ti}$ (referred to as common $\mathrm{A}$ ) and for phase $\mathrm{B}$ it was 38-47C/22-27Si/31-35Ti (referred to as common $\mathrm{B}$ ). There were differences among the four joints regarding the presence of a third phase (phase C) and its composition. For the joint from the $10 \mu \mathrm{m}$ Ti foil processed for $2 \mathrm{~h}$, the third phase had a composition of $37 \mathrm{C} / 43 \mathrm{Si} / 20 \mathrm{Ti}$. The relatively high $\mathrm{Si}$ content may help increase ductility in this phase so that 


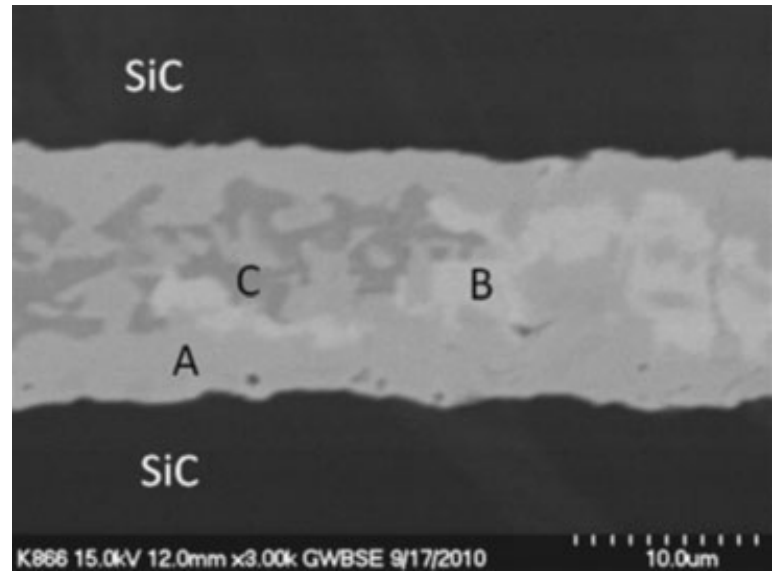

Fig. 5. SEM micrograph of the diffusion bond from $10 \mu \mathrm{m} \mathrm{Ti}$ foil at $1200^{\circ} \mathrm{C}$ with 2 h-hold.

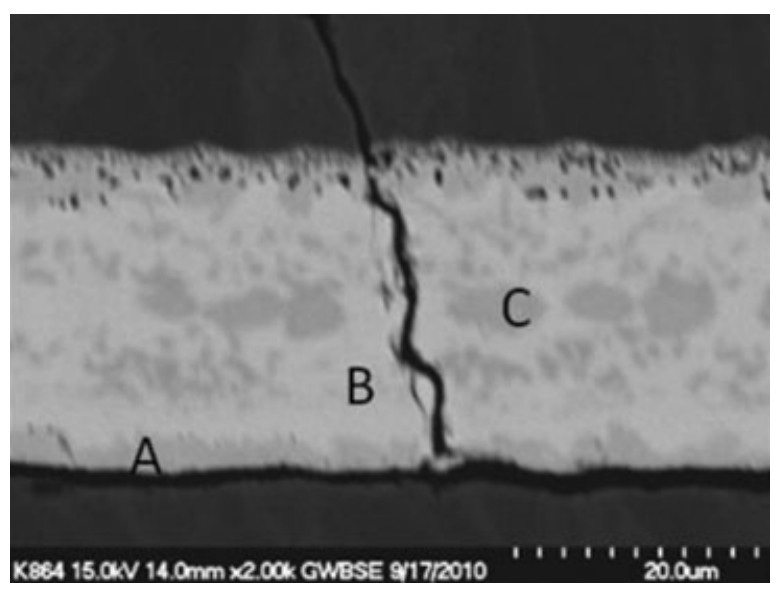

Fig. 6. SEM micrograph of the diffusion bond from $20 \mu \mathrm{m} \mathrm{Ti}$ foil at $1200^{\circ} \mathrm{C}$ with 1 h-hold.

stresses are alleviated and microcracks do not form. For the joints formed with the $20 \mu \mathrm{m}$ Ti foil processed for $1 \mathrm{~h}$ and $2 \mathrm{~h}$, the third phase (phase $\mathrm{C}$ in the two micrographs) had a composition of 57-58C/1-7Si/3542Ti (referred to in Table I as "common A with lower Si content"). This phase which occurs at the core of the joint may be an intermediate phase that transitions to the composition of phase $\mathrm{A}$ as more $\mathrm{Si}$ diffuses from the $\mathrm{SiC}$ substrate. In these two bonds, phases $\mathrm{A}$ and $\mathrm{C}$ with their low silicon content may be less ductile and therefore may contribute to the observed microcracking. In the joint formed with $20 \mu \mathrm{m}$ Ti foil processed for $4 \mathrm{~h}$, smaller microcracks were observed. The presence of phase A with its slightly higher Si content and the absence of phase $\mathrm{C}$ with its lower Si content may

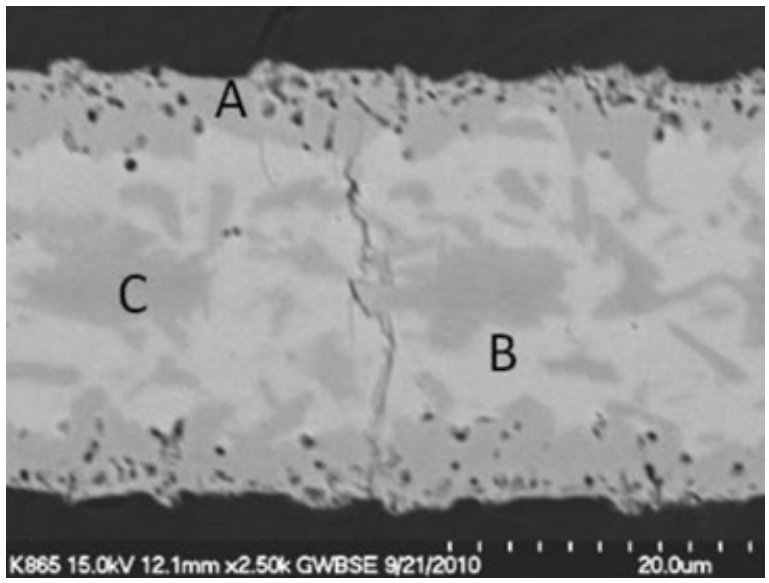

Fig. 7. SEM micrograph of the diffusion bond from $20 \mu \mathrm{m} \mathrm{Ti}$ foil at $1200^{\circ} \mathrm{C}$ with 2 h-hold.

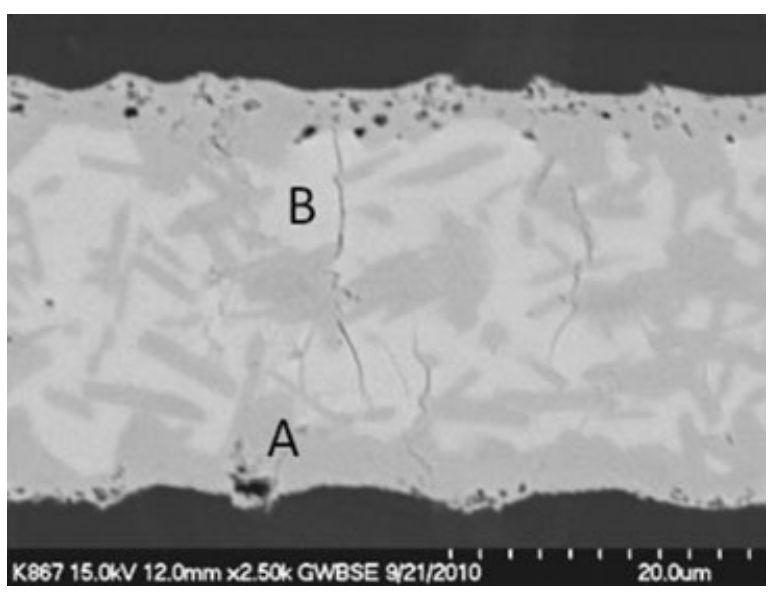

Fig. 8. SEM micrograph of the diffusion bond from $20 \mu \mathrm{m} \mathrm{Ti}$ foil at $1200^{\circ} \mathrm{C}$ with 4 h-hold.

contribute to slightly higher ductility and less cracking. In general, the phases formed in the joints formed with the Ti foil were carbon rich. The formation mechanism of these phases is still being investigated and will be reported in a future publication.

Transmission electron microscopy was conducted on the diffusion bonds formed with 10 and $20 \mu \mathrm{m}$ PVD coatings, $10 \mu \mathrm{m}$ Ti foil held for $2 \mathrm{~h}$, and $20 \mu \mathrm{m}$ Ti foil held for $2 \mathrm{~h}$. Micrographs of each sample are shown in Figs. 9-12. Selected areas where diffraction (SAD) patterns have been taken are shown in numerical order. Although not pointed out in the micrographs, $\mathrm{SAD}$ patterns of $\mathrm{SiC}$ within the substrate region were also taken for each sample. In all specimens, 3C-SiC was identified in the substrate region. In 
(a)

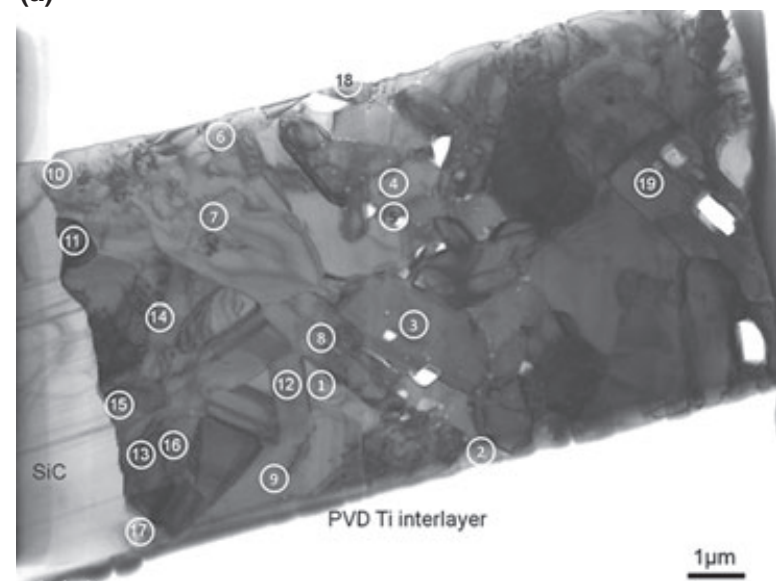

(b)

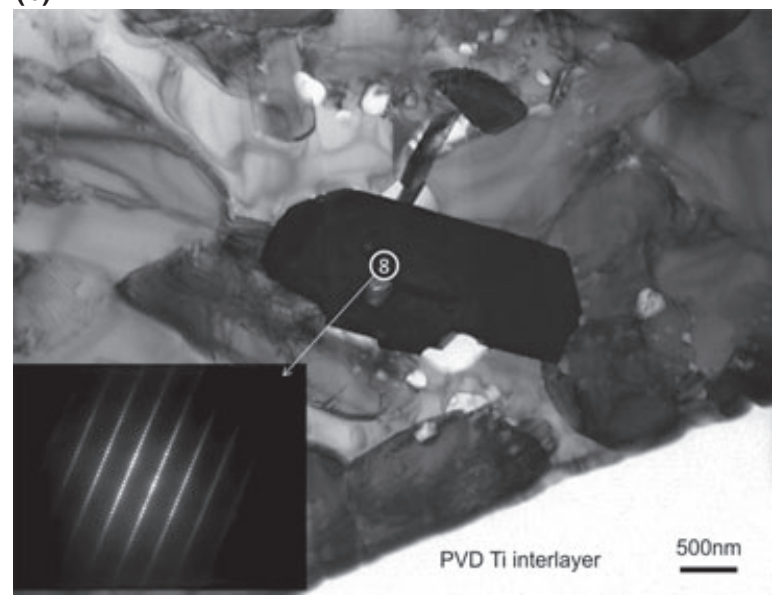

Fig. 9. (a) TEM micrograph of the diffusion bond from $10 \mu \mathrm{m}$ PVD Ti at $1250^{\circ} \mathrm{C}$ with 2 h-hold; and 9 (b) Enlarged TEM micrograph of Fig. 9 (a) and SAD pattern obtained from the location 8.

addition, twin spots and the streaks perpendicular to the [111] direction of $\mathrm{SiC}$ in SAD pattern were observed, suggesting that this 3C-SiC may contain many micro-twins or stacking faults. The TEM micrograph of the diffusion bond formed with the $10 \mu \mathrm{m}$ PVD $\mathrm{Ti}$ coating interlayer held at $1250^{\circ} \mathrm{C}$ for $2 \mathrm{~h}$ is shown in Fig. 9a. The diffusion bond consists of many reaction-formed grains with lengths of $1 \sim 2 \mu \mathrm{m}$ and widths of $0.5-1.5 \mu \mathrm{m}$. In Fig. $9 \mathrm{~b}$ is shown an enlarged micrograph of the vicinity of the location 8 of Fig. 9a, and its corresponding SAD pattern of the phase. The SAD pattern identified this phase as $\mathrm{Ti}_{3} \mathrm{SiC}_{2}$ (hexagonal crystal structure [space group; $\mathrm{P}_{3} / \mathrm{mmc}$ ], lattice constant; $\mathrm{a}=0.3068 \mathrm{~nm}, \mathrm{C}=1.7669 \mathrm{~nm}^{35}$ ). In addition,

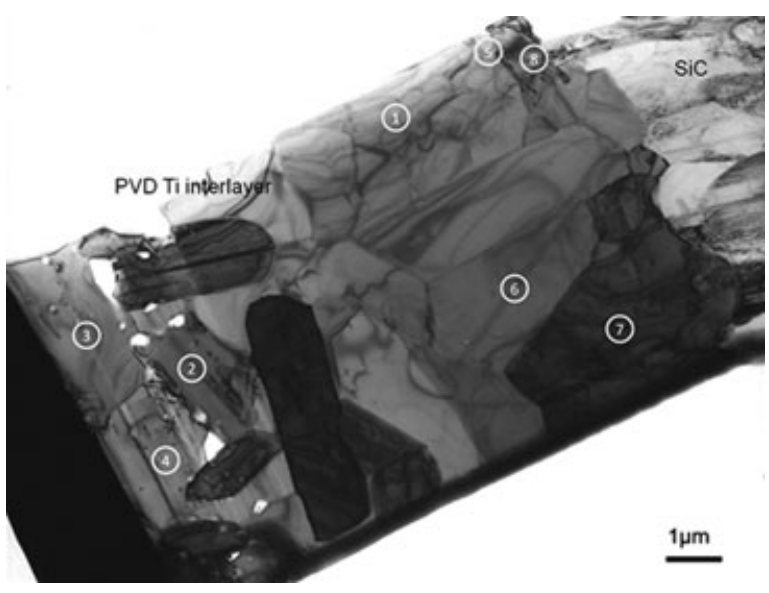

Fig. 10. TEM micrograph of the diffusion bond from $20 \mu \mathrm{m}$ PVD Ti at $1250^{\circ} \mathrm{C}$ with 2 h-hold.

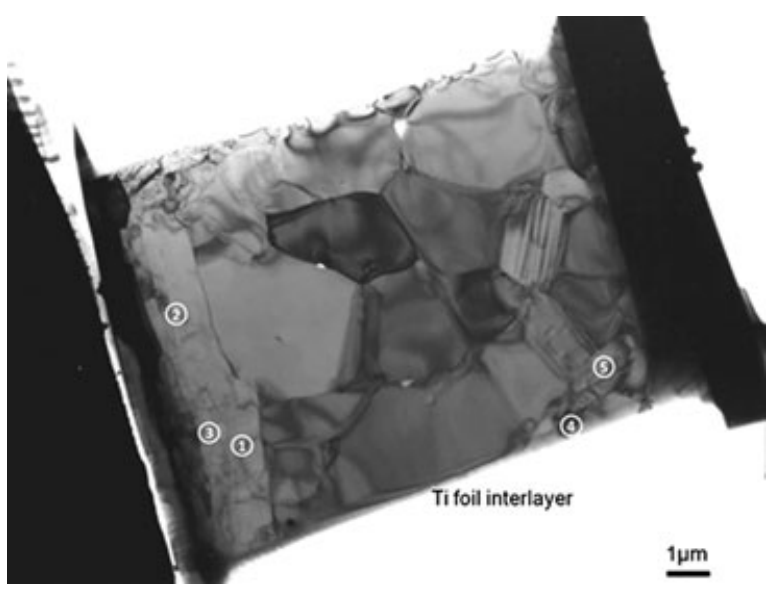

Fig. 11. TEM micrograph of the diffusion bond from $10 \mu \mathrm{m}$ Ti foil at $1200^{\circ} \mathrm{C}$ with $2 \mathrm{~h}$-hold.

the incident beam direction is [11-20] of $\mathrm{Ti}_{3} \mathrm{SiC}_{2}$. Judging from analysis of SAD pattern obtained, it is obvious that the reaction formed phase at locations 6-10 and 13-19 is $\mathrm{Ti}_{3} \mathrm{SiC}_{2}$. Therefore, the dominant phase of the diffusion bond formed with the $10 \mu \mathrm{m}$ PVD Ti coating interlayer is $\mathrm{Ti}_{3} \mathrm{SiC}_{2}$; it is consistent with EMPA observation described before. A TEM micrograph of the diffusion bond from $20 \mu \mathrm{m}$ PVD Ti at $1250^{\circ} \mathrm{C}$ with $2 \mathrm{~h}$-hold is shown in Fig. 10 . At locations 2 and $5-8, \mathrm{Ti}_{3} \mathrm{SiC}_{2}$ was identified. This phase was also observed in this sample in the EMPA.

On the other hand, TEM micrographs of diffusion bonds from 10 and $20 \mu \mathrm{m}$ Ti foils at $1200^{\circ} \mathrm{C}$ with 2 h-hold are shown in Figs. 11 and 12. SAD patterns identified $\mathrm{Ti}_{3} \mathrm{SiC}_{2}$ at locations $1-5$ of $10 \mu \mathrm{m}$ Ti foil, 


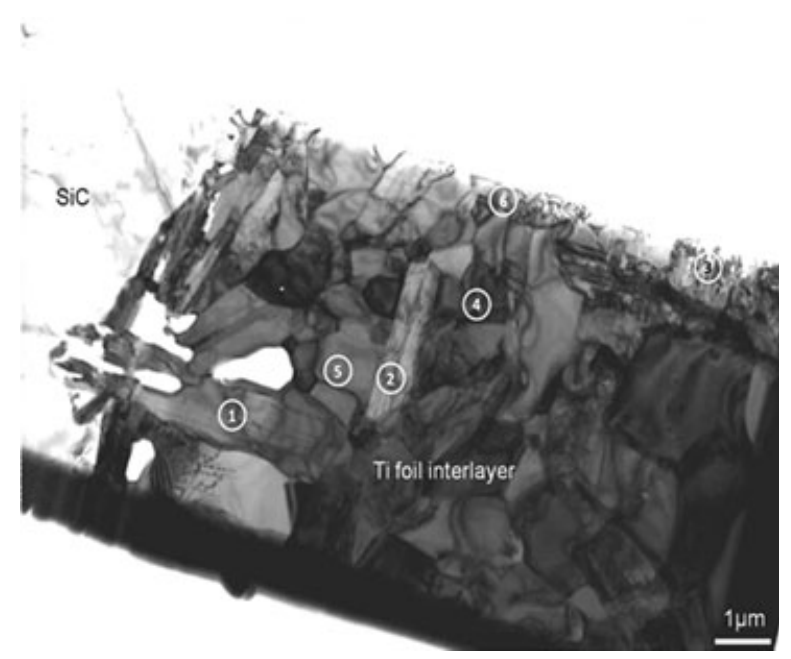

Fig. 12. TEM micrograph of the diffusion bond from $20 \mu \mathrm{m}$ Ti foil at $1200^{\circ} \mathrm{C}$ with 2 h-hold.

and at locations 1, 2, and 6 of $20 \mu \mathrm{m}$ Ti foil. In the TEM, additional phases have been observed but have not yet been positively identified. In the Ti-Si-C ternary system, other researchers ${ }^{28,29,34,36,37}$ have reported the presence of not only $\mathrm{Ti}_{3} \mathrm{SiC}_{2}$ but also other phases, such as $\mathrm{Ti}_{5} \mathrm{Si}_{3} \mathrm{C}_{\mathrm{x}}, \mathrm{TiC}$, and $\mathrm{TiSi}_{2}$ in the reacted interface between $\mathrm{SiC}$ and $\mathrm{Ti}$ at high temperature. More detailed analysis is required to understand the phase formation in the present work and to positively identify the additional phases.

\section{NDE and Mechanical Testing of Joints}

The NDE method of ultrasonic immersion was conducted on the two joined sets of $2.54 \mathrm{~cm}$ diameter disks with a $10 \mu \mathrm{m}$ thick PVD Ti coating applied to the $1.66 \mathrm{~cm}$ inner diameter of the substrate. The ultrasonic immersion method uses an ultrasonic pulse which is emitted and enters the specimen. The difference between the amount of signal that reflects back at the interface and at the backside of the sample determines bond quality. Less deflection at the bond interface correlates with good bonding. The NDE image of the joint formed with the polished $\mathrm{SiC}$ disks is shown in Fig. 13. The image from the joined, unpolished $\mathrm{SiC}$ substrates was similar. The NDE results show both sets of joined disks, had good quality, uniform bonds. No delaminations were observed. The strength data from the tensile test are shown in Fig. 14. Failures occurred at 13.4 and 15.0 $\mathrm{MPa}$ for the unpolished and surface-polished sets of

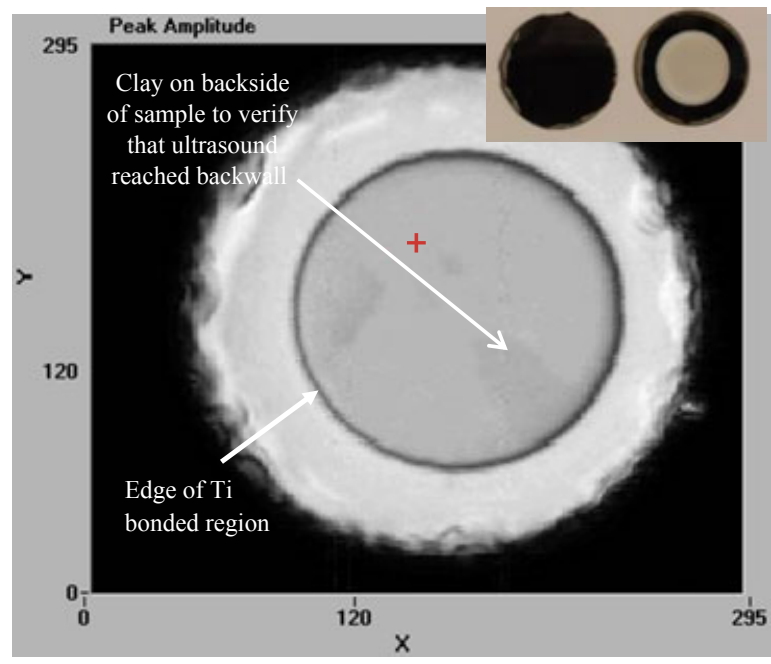

Fig. 13. Results from ultrasonic immersion for the more polished pair of joined substrates. The inset image shows the appearance of the uncoated and Ti-coated disks before joining.

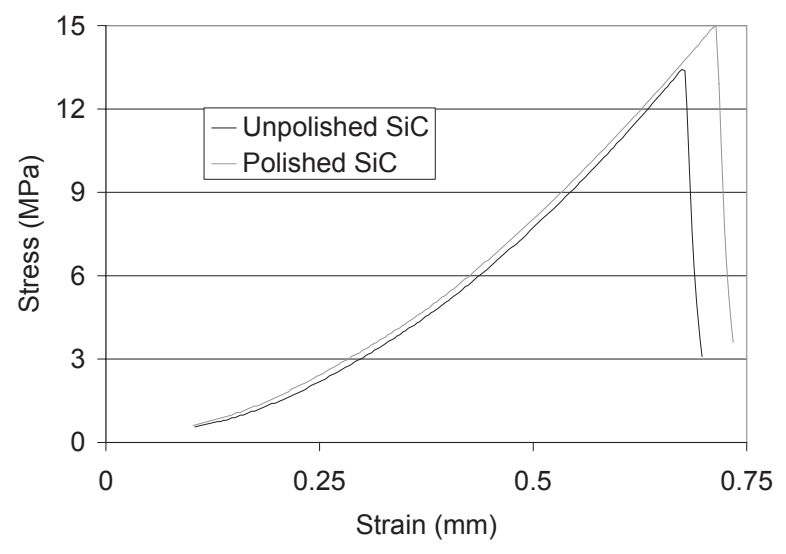

Fig. 14. Stress versus strain curves for the two sets of joined disks.

joined substrates, respectively. The failures occurred primarily in the $\mathrm{SiC}$ region rather than in the bond region. The strength of the diffusion bonds was well above the requirements of the injector application which is about 3.5-7.0 MPa. Diffusion bonding with a $10 \mu \mathrm{m}$ thick PVD $\mathrm{Ti}$ interlayer was demonstrated on larger parts that were $10.16 \mathrm{~cm}$ in diameter (Fig. 15a). An image of the joined disks and SEM micrographs from a polished section are shown in Fig. 15b-c. The small isolated pores are not expected to have a significant effect on the strength and leak-free properties of the joint. The bond quality was very similar to the 
(a)

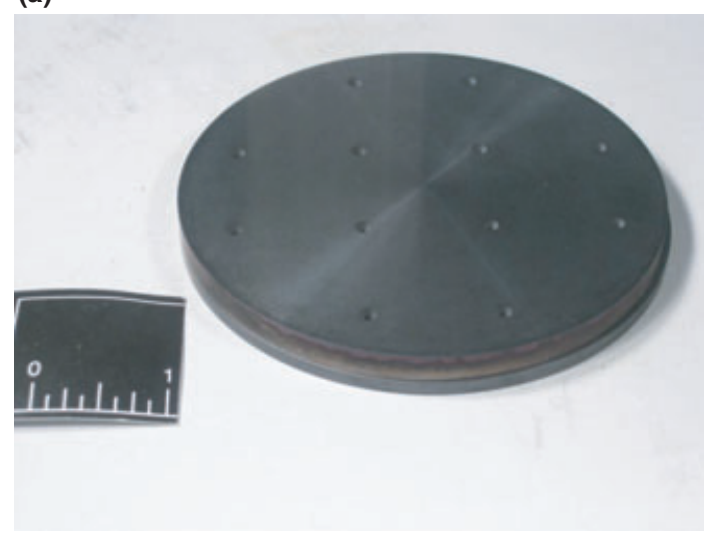

(b)

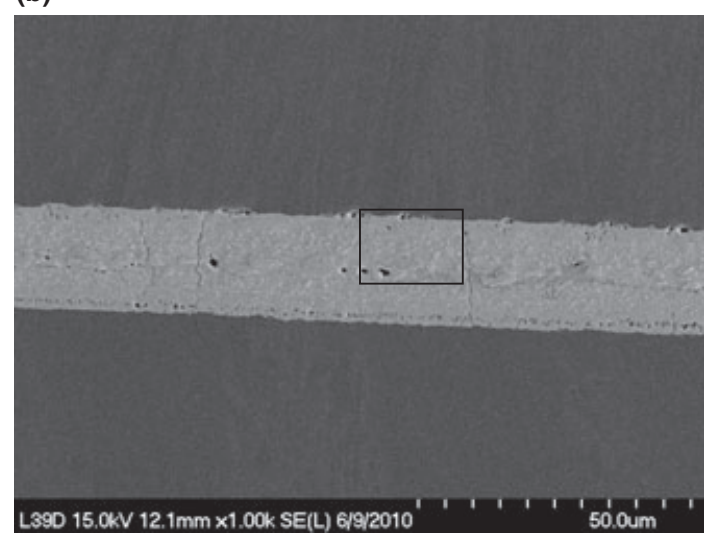

(c)

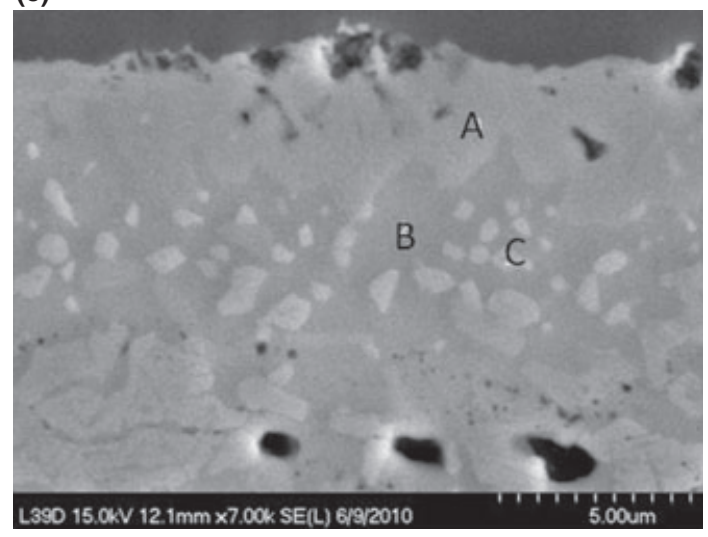

Fig. 15. (a) Image of the $10.16 \mathrm{~cm}$ diameter disks that were joined, (b) micrograph of the resulting diffusion bond, and (c) a higher magnification view where EDS was conducted at three locations.

bonds formed with the $20 \mu \mathrm{m}$ Ti foil. Similarities included microcracking and the presence of the same phases as identified in the joints formed with the
$20 \mu \mathrm{m} \mathrm{Ti}$ foil at 1 and $2 \mathrm{~h}$-holds. These phases were observed in bonds formed with both types of interlayers (Ti foil and PVD Ti). Further analysis is needed to identify the phases and to explain the high carbon content compared to the two diffusion bonds formed with the 10 and $20 \mu \mathrm{m}$ PVD Ti interlayer. Differences in the analysis and processing that could account for the different phases include different EDS systems for the EMPA and SEM analysis and the use of different $\mathrm{SiC}$ substrates. The $\mathrm{SiC}$ substrates used to bond the $10.16 \mathrm{~cm}$ diameter disks and form bonds with the Ti foil had high carbon contents of $57-60$ at.\% with silicon as the remaining percentage.

\section{Conclusions}

Diffusion bonding is an enabling technology for the fabrication of a silicon carbide MEMS lean direct injector for jet engines. The effects of the interlayer type, interlayer thickness, and processing hold times were investigated. For the PVD Ti interlayers, the $10 \mu \mathrm{m}$ interlayer gave the best results with a joint that did not have intermediate phases or microcracking. For the $\mathrm{Ti}$ foil interlayer, the joint processed with a $4 \mathrm{~h}$ hold had more stable phases and less microcracking than those with 1 and 2 h-holds. Phases that contributed to microcracking were the anisotropic $\mathrm{Ti}_{5} \mathrm{Si}_{3} \mathrm{C}_{\mathrm{x}}$ phase and phases with compositions in the range of 4458C/1-14Si/33-42Ti. The average tensile strength of the diffusion bonds was $14.2 \mathrm{MPa}$ which is 2-3 times higher than that in the injector application requirements. The NDE method of ultrasonic immersion showed that the diffusion bonds were uniform with no delaminations. The diffusion bonding method was demonstrated on disks of $10.16 \mathrm{~cm}$ diameter which is of the same diameter as the injector. Diffusion bonding was shown to meet the strength, stability, and microstructural requirements for joining the $\mathrm{SiC}$ laminates for injector fabrication. Future efforts will include fabricating the actual injector parts and demonstrating leak-free operation.

\section{Acknowledgments}

This effort was supported by the NASA Glenn Research Center under the Subsonic Fixed Wing Project. The authors would like to thank James Smith for 
conducting microprobe analysis, Dr. Robert Okojie for applying PVD Ti coatings, and Robert Angus for hot pressing. The authors would also like to thank Richard E. Martin and Laura M. Cosgriff of Cleveland State University for conducting NDE.

\section{References}

1. P. Lundberg and B. Lundberg, "Transition Between Interface Defeat and Penetration for Tungsten Projectiles and Four Silicon Carbide Materials," Int. J. Impact Eng., 31 781-792 (2005).

2. G. Kroetz, W. Wondrak, E. Obermeier, and C. Cavalloni, "Silicon Carbide on Silicon-an Ideal Material Combination for Harsh Environment Sensor Applications," Industrial Electronics, Proceedings ISIE '98 IEEE International Symposium, July 7-10, 1998; 2 [2] 732-736 (1998),

3. D. G. Senesky, B. Jamshidi, K. B. Cheng, and A. P. Pisano, "Harsh Environment Silicon Carbide Sensors for Health and Performance Monitoring of Aerospace Systems: A Review," IEEE Sens. J., 9 [11] 1472-1478 (2009).

4. M. Avram, A. Avram, A. Bragaru, B. Chen, D. P. Poenar, and C. Iliescu, "Low Stress PECVD Amorphous Silicon Carbide for MEMS Applications," Semic. Conf. CAS 2010 Int., 1 239-242 (2010).

5. P. M. Sarro, "Silicon Carbide as a New MEMS Technology," Sens. Act. A: Phys., 82 [1-3] 210-218 (2000).

6. M. Mehregany and C. A. Zorman, "SiC MEMS: Opportunities and Challenges for Applications in Harsh Environments," Sens. Act., 82 210-218 (2000).

7. C. Hille, W. Lippmann, M. Herrmann, and A. Hurtado, "Non-Oxide Ceramics: Chances for Application in Nuclear Hydrogen Production," Proceedings of the 16th International Conference on Nuclear Engineering, ICONE16, Orlando, FL, May 11-15, 2008.

8. W. Yao, Y. Zhang, J. Han, and H. Zuo, "Fabrication and Test of Reaction Bonded Silicon Carbide for Optical Applications," Trans. Nonf. Met. China, 16 [2] 409-413 (2006).

9. S. Suyama, Y. Itoh, K. Tsuno, K. Ohno, and H. Irikado, "Development of Joining Technology of High-Strength Reaction-Sintered Silicon Carbide for Optical Mirror," Proceedings ICSO 2008, International Conference on Space Optics, Toulouse, France, October 14-17, 2008.

10. T. Hino, E. Hayashishita, Y. Yamauchi, M. Hashiba, Y. Hirohata, and A. Kohyama, "Helium Gas Permeability of $\mathrm{SiC} / \mathrm{SiC}$ Composite Used for InVessel Components of Nuclear Fusion Reactor," Fus. Eng. Des., 73 51-56 (2005).

11. Y. Hirohata et al. "Gas Permeability of $\mathrm{SiC} / \mathrm{SiC}$ Composites as Fusion Reactor Material,” Fus. Eng. Des., 61-62 699-704 (2002).

12. R. Naslain, "Design, Preparation and Properties of Non-Oxide CMCs for Application in Engines and Nuclear Reactors: An Overview," Compos. Sci. Technol., 64 155-170 (2004).

13. P. Spriet and G. Habarou, "Application of CMCs to Turbojet Engines: Overview of the SEP Experience," Key Eng. Mat., 127-131 1267-1276 (1997).

14. J. Kimmel et al. "Evaluation of CFCC Liners with EBC After Field Testing in a Gas Turbine," J. Eur. Ceram. Soc., 22 2769-2775 (2002).

15. M. Van Roode et al. "Ceramic Matrix Composite Combustion Liners: A Summary of Field Evaluations," J. Eng. Gas Turb. Power, 129 21-30 (2007).

16. R. S. Okojie, R. Tacina, C. Wey, and C. Blaha, "Micro Fabrication of $\mathrm{SiC}$ Mesoscale Lean Direct Injector Array: Toward Active Combustion
Control," Solid-State Sensors, Actuators and Microsystems Conference, 2007. TRANSDUCERS 2007 International, Lyon, France, June 10-14, 2007.

17. R. Tacina, C. Wey, P. Laing, and A. Mansour, "A Low Lean Direct Injection, Multipoint Integrated Module Combustor Concept for Advanced Aircraft Gas Turbines," NASA/TM-2002-211347, April 2002.

18. S.-B. Li, M.-L. Maa, J.-Q. Gaob, and Z.-H. Jin, "Reaction Forming of Joints in Silicon Carbide Ceramic Materials," Mat. Sci. Eng. A, 483-484 747-750 (2008).

19. M. Singh, "A Reaction Forming Method for Joining of Silicon CarbideBased Ceramics," Scr. Mater., 37 [8] 1151-1154 (1997).

20. J. Martínez Fernandez, A. Munoz, F. M. Valera-Feria, and M. Singh, "Interfacial and Thermal Characterization of Reaction Formed Joints in Silicon Carbide-Based Materials," J. Eur. Ceram. Soc., 20 2641-2648 (2000).

21. P. Colombo et al. "Joining SiC-Based Ceramics and Composites with Pre-Ceramic Polymers," Ceram. Trans., 144 323-334 (2002).

22. E. Pippel, J. Woltersdorf, P. Colombo, and A. Donato, "Structure and Composition of Interlayers in Joints Between SiC Bodies," J. Eur. Ceram. Soc., 17 1259-1265 (1997).

23. Y. Liu, Z. R. Huang, and X. J. Liu, "Joining of Sintered Silicon Carbide Using Ternary Ag-Cu-Ti Active Brazing Alloy," Ceram. Int., 35 [8] 3479 -3484 (2009).

24. M. R. Locatelli, B. J. Dalgleish, K. Nakashima, A. P. Tomsia, and A. M. Glaeser, "New Approaches to Joining Ceramics for High-Temperature Applications," Ceram. Int., 23 313-322 (1997).

25. K. Kakegawa and A. M. Glaeser, "Transient FGM Joining of Silicon Carbide Ceramics: A Feasibility Study," Composites Part B, 28 [1-2] 85-91 (1997).

26. J. Li and P. Xiao, "Fabrication and Characterization of Silicon Carbide/ Superalloy Interfaces," J. Eur. Ceram. Soc., 24 2149-2156 (2004).

27. K. Bhanumurthy and R. Schmid-Fetzer, "Solid-State Bonding of Silicon Carbide (HIP-SiC) Below $1000^{\circ}$ C," Mat. Sci. Eng. A, 220 [1-2] 35-40 (1996).

28. B. V. Cockeram, "The Diffusion Bonding of Silicon Carbide and Boron Carbide Using Refractory Metals," Proceedings from the ASM Materials Solution 99: International Conference on Joining of Advanced and Specialty Metals, Cincinnati, OH (US), October 1, 1999.

29. B. Gottselig, E. Gyarmati, A. Naoumidis, and H. Nickel, "Joining of Ceramics Demonstrated by the Example of SiC/Ti," J. Eur. Ceram. Soc., 6 153-160 (1990).

30. J. Ayanne, L. Beaunier, J. Boumendil, G. Ehret, and D. Laub, Sample Preparation Handbook for Transmission Electron Microscopy: Techniques, 1st edition, Springer, New York, 2010, p. 135.

31. J. H. Schneibel, C. J. Rawn, E. A. Payzant, and C. L. Fu, "Controlling the Thermal Expansion Anisotropy of $\mathrm{Mo}_{5} \mathrm{Si}_{3}$ and $\mathrm{Ti}_{5} \mathrm{Si}_{3}$ Silicides," Intermetallics, 12 845-850 (2004).

32. J. H. Schneibel and C. J. Rawn, "Thermal Expansion Anisotropy of Ternary Silicides Based on $\mathrm{Ti}_{5} \mathrm{Si}_{3}$," Acta Mater., 52 3843-3848 (2004).

33. L. Zhang and J. Wu, "Thermal Expansion and Elastic Moduli of the Silicide Based Intermetallic Alloys $\mathrm{Ti}_{5} \mathrm{Si}_{3}(\mathrm{X})$ and $\mathrm{Nb}_{5} \mathrm{Si}_{3}$," Scripta Materiallia, 38 [2] 307-313 (1998).

34. M. Naka, J. C. Feng, and J. C. Schuster, "Phase Reaction and Diffusion Path of the SiC/Ti System," Metall. and Mat. Trans. A., 24A 1385-1390 (1997).

35. P. Villars, Pearson's Handbook: Crystallographic Data for Intermetallic Phases, ASM International, Materials Park, OH, 1997.

36. M. Naka, J. Feng, and J. C. Schuster, "Phase Stability of SiC Against Ti at High Temperature," Vacuum, 83 [1] 223-325 (2009).

37. S. Gorsse and Y. Le Petitcorps, "A New Approach to the Understanding of the SiC/Ti Reaction Zone Composition and Morphology," Composites Part A: Applied Science and Manufacturing (Incorporating Composites and Composites Manufacturing), 29 [9] 1221-1227 (1998). 